\title{
Efeito dominó na América Latina: influência do sistema internacional nos regimes políticos
}

\author{
Ítalo Beltrão Sposito*
}

\begin{abstract}
Resumo
Este artigo busca encontrar fatores internacionais influentes nos processos de ascensão de regimes autocráticos e democratização ocorridos na América Latina durante, respectivamente, as décadas de 1960 e 1970, e as décadas de 1980 e 1990. Além de considerar os fatores endógenos que foram determinantes nesses processos, são investigadas as principais influências externas sobre as mudanças de regime democrático.

Os fatores considerados são: a influência dos Estados Unidos sobre a região, no primeiro processo, a partir dos programas de assistência militar e da incorporação de sua Doutrina de Segurança Nacional por parte das escolas superiores de guerra em diversos países da América Latina e, no segundo processo, pela guinada em sua política em relação à região, quando passou a defender os valores democráticos e evitar ajuda a regimes autocráticos. 0 sistema internacional - no primeiro momento caracterizado pela bipolarização ideológica da Guerra Fria - levou à radicalização das posturas políticas nos países da América Latina em um momento crucial de seu processo de desenvolvimento, como resultado a ascensão de ideologias de cunho anticomunista. No período de democratização, a política internacional pode ter sido um fator influente pela consideração de que os regimes democráticos se tornara um imperativo para se inserir na economia internacional.
\end{abstract}

\section{Iniciando o debate}

Para abrir o artigo, será feito um panorama sobre as tentativas de diversas correntes de encontrar explicações sobre os determinantes para a formação de um regime democrático e sobre sua manutenção; após, será inserida uma discussão sobre a utilização de fatores exógenos para analisar as principais variáveis dependentes da literatura de política comparada - condições para formação de um regime democrático e para garantir sua estabilidade.

Pesquisas de política comparada sobre mudanças de regime político e estabilidade de regimes democráticos utilizaram, tradicionalmente, fatores e variáveis explicativas relacionadas a questões estruturais domésticas e de política interna para explicar as rupturas e transições de regime que se concretizaram através das disputas

\footnotetext{
Doutorando e Mestre em Relação Internacionais pelo IRI-USP, com Graduação em Relações Internacionais pela UNESP e Especialização em Integração Latino-americana pela UFPR.
} 
entre elites políticas de cada Estado. Essas correntes se concentraram em desenvolver definições mínimas/gerais e graduações/tipologias de democracia de modo classificar os regimes, para assim, encontrar variáveis que expliquem o modelo dos regimes políticos nacionais a partir de diferentes indicadores de características políticas, econômicas, sociais e culturais domésticas. O maior consenso na literatura da área é quanto à correlação existente entre estabilidade democrática e desenvolvimento econômico. Przeworski (2001) comprovou empiricamente a tese de que a riqueza de um país pode ser determinante na manutenção de um regime democrático ao encontrar correlações estatisticamente significantes entre a renda per capita e a estabilidade desse tipo de regime.

A partir destes avanços, a maioria das investigações que buscam novas variáveis para explicar o nível de democracia ou a estabilidade de tal regime em um país, a partir de variáveis exógenas, controla a variável de desenvolvimento econômico para que os resultados obtidos, baseados em influências externas, sejam enviesados (Bollen, 1983; Brinks e Coppedge, 2006; Cheibub, 2007; Gledistsch e Ward, 2006; O'Laughlin et al. 1998; Wejnert, 2005).

A teoria da modernização, que surgiu com a expansão dos regimes democráticos ocorrida no período posterior à 2a Guerra Mundial, defendeu a tese de que a ascensão de regimes democráticos resultou dos movimentos de libertação nacionais. Esta corrente busca relacionar as condições históricas, conjunturais e do sistema político com o desenvolvimento e, principalmente, a estabilidade dos regimes democráticos. Lipset (1967) buscou comprovar a hipótese de que existem requisitos sociais à implantação da democracia ao afirmar que o nível de desenvolvimento influencia positivamente nesse processo. Huntington (1975) alega que há dificuldade em assimilar novos grupos oriundos da modernização da sociedade, e, portanto, considera necessário a melhora e a modernização das instituições para possibilitar a posterior inclusão desses grupos na participação política. A teoria da modernização considera, em linhas gerais, que o desenvolvimento e a modernização das sociedades permitem a formação de uma classe média relativamente abastada e menores graus de desigualdade social, dificultando o descontentamento e possível formação de grupos extremistas e de caráter revolucionário. A existência das classes médias e a 
preferência por partidos moderados incentivariam a manutenção das "regras do jogo" democrático e seu respeito pela oposição. (Lipset, 1967; Moore, 1975). No entanto, este tipo de abordagem foi considerado determinista por se basear em uma relação causal entre condições histórico-sociais e o surgimento de um tipo de regime político. A ascensão de regimes militares na América Latina, como resultado da modernização, acabou por enfraquecer as teses desta corrente de política comparada.

É nesse contexto que O’Donnell (1973) apresenta uma tese oposta. Ele defende a idéia de que, em países com altos níves de desigualdade política e econômica, o advento da modernização resultaria na ascensão de regimes autoritário-burocráticos, através de um processo que se inicia com o aumento do poder político das classes baixas, problemas econômicos pelo fim da fase de Industrialização por Substituição de Importações (ISI) e pelo aumento da importância do papel dos tecnocratas. O aumento do poder popular, resultante de mudanças estruturais da sociedade, é considerado pelos tecnocratas como responsável pelo colapso do sistema político-econômico; a explicação seria que, como resposta a busca por mudanças estruturais, as elites formaram coalizões com o objetivo de manter o status quo e: a) garantir a exclusão dos segmentos populares, b) buscar a maximização do desempenho econômico, e c) superar a estagnação a partir de seu conhecimento técnico. Apesar de apresentar uma inovação para explicar a ascensão dos regimes militares na América do Sul, suas teses, quando investigadas posteriormente, não obtiveram embasamento empírico, além disso, as fases posteriores ao golpe militar descritas pelo autor são generalizações do caso brasileiro e, assim como os teóricos da modernização, ele utiliza relações causais deterministas para explicar um fenômeno singular na história mundial (Remmer e Merkx, 1982).

O desenvolvimento material das sociedades industrializadas durante as décadas de 1960 e 1970, que ocorreu principalmente nos Estados Unidos e Europa Ocidental, diminuiu as preocupações materiais e de curto prazo relacionadas à sobrevivência e fez emergir novos temas chamados de "pós-materialistas" a serem contemplados pelas políticas públicas. Uma mudança no nível sistêmico, que significou a estabilidade política e econômica das populações nesses países, resultou em câmbios de valores no nível individual pela ascensão de reivindicações em temas relacionados 
ao meio ambiente ou aos direitos humanos, que por sua vez, passaram a influenciar o sistema político.

Este processo levantou hipóteses que deram origem a outra abordagem para explicar as condições necessárias ao desenvolvimento da democracia: a cultura política. No entanto, essa corrente está mais preocupada com os fatores determinantes no desempenho constitucional dos regimes democráticos. Almond e Verba (1963), Putnam, Leonardi e Nanetti (1993), e Newton e Norris (2000) defendem a hipótese de que determinados aspectos culturais, normas e valores são favoráveis ao desenvolvimento de um sistema político democrático. Assim, esses autores procuram relações entre o desempenho institucional de um governo e os níveis de confiança da população sobre os mesmos, ou seja, investigam se o nível social agregado de confiança (capital social) e a confiança nas instituições políticas estão correlacionados, através de uma análise baseada em surveys.

Przeworski et al. (2000) sublinham a falta de evidências empíricas das concepções culturalistas porque elas levam em consideração a existência de relações entre cultura cívica e estabilidade democrática e afirmam que algumas culturas são mais incompatíveis com o sistema democrático. Os autores consideram difícil a identificação de traços da cultura que sejam determinantes sobre o desempenho dos governos, assim como a determinação de elos causais entre instituições políticas, e cultura ou níveis de confiança. Portanto, defendem uma visão não culturalista de que a democracia emerge e se mantém de modo independente da cultura.

No final do século XX, a noção de que existiram "ondas" de democratização alertou pesquisadores sobre a possibilidade de se utilizar fatores internacionais para explicar as tendências de mudanças nos regimes políticos nacionais; afinal, dois eventos históricos mundiais foram decisivamente influentes para a segunda e a terceira "ondas" de democratização, respectivamente, o final da Segunda Guerra Mundial e o fim da Guerra Fria. (Huntington, 1991). Este período, da chamada "terceira onda" de democratização, caracterizado pela ascensão de regimes democráticos em diversas partes do mundo, incentivou pesquisadores a buscarem explicações para as causas de possíveis movimentos de difusão de regimes políticos. 
Correntes influenciadas pelos estudos de Política Internacional e de Geografia passaram a incorporar fatores externos para explicar as mudanças de regime político. Gleditsch (1999) demonstra que fatores internacionais, tais como os regimes políticos em Estados vizinhos e pressões regionais podem influenciar um país a passar por uma transição de regime. Dentro desta linha, O'laughlin et al. (1998) realizaram um estudo para investigar as regularidades espaciais e temporais - processos de mudanças de regime ocorridos contemporaneamente ou em determinado contexto regional - do processo de difusão democrática e encontraram evidências de congruência temporal entre tendências de regime e associação espacial da democratização. Além disso, Gleditsch e Ward (2006) encontraram evidências de que o número total de regimes políticos democráticos dentro do sistema internacional tem influência sobre a possibilidade de transição democrática.

A relevância de fatores externos para explicar mudanças nos regimes políticos nacionais é muito questionada pela simples crença de que as questões políticas internas são moldadas pelas relações entre as elites e os atores influentes no jogo nacional, tendo as forças internacionais apenas influência marginal nas transições de regimes políticos. No entanto, o século XX foi marcado pelo exponencial aumento das relações de interdependência no mundo e pela disputa de blocos em torno de ideologias políticas - como na Segunda Guerra Mundial, entre as democracias ocidentais e o nazi-facismo, e na Guerra Fria entre o comunismo e o capitalismo - que aproximaram a disputa no sistema internacional do tema do regime político doméstico.

Raymond Aron (2002) alerta para a influência da política internacional nos regimes políticos internos. O autor considera que a existência de regimes políticos parecidos facilita a formação de alianças entre Estados e que, dentro de sistemas heterogêneos - compostos por Estados com valores político-ideológicos diferentes há Estados com regimes internos antagônicos que apresentam riscos para a estabilidade e legitimidade interna do regime de outro ator. Isso significa que a presença de determinado Estado com direcionamento político-ideológica " $A$ " dentro do sistema internacional (SI) pode representar uma fonte de poder para uma classe social de ideologia análoga dentro de outro Estado que tenha regime político e/ou ideologia oposta ("B"). 
Outros autores de política internacional, tais como Waltz (1979) e Keohane (1984) estudam o papel de uma potência hegemônica no SI, o que poderia influenciar o comportamento dos outros atores na arena internacional, tal como os Estados Unidos desde o final da Segunda Guerra Mundial. Este país, além de mobilizar forças militares em escala mundial que garantam seus interesses, utilizou intervenções militares em áreas de influência direta (principalmente na América Central no período entre 1950 e 1990) para garantir no poder, elites políticas simpatizantes aos seus objetivos, resultando em rupturas nos regimes políticos internos (Holden, 1993 e 1999). Além disso, o apoio a regimes de cunho anticomunista foi uma prática corrente para garantir a manutenção do sistema capitalista nessas áreas, o que também resultou em mudanças na natureza dos regimes. O forte apoio a tais doutrinas (baseadas na leitura da política mundial bipolarizada) enfatizava a importância da segurança nacional para conter o avanço de forças internas partidárias dos ideais comunistas. Isso influenciou e aumentou o apoio doméstico à legitimidade das políticas desenvolvidas nas escolas militares superiores em países da América do Sul, fato que abriu caminho à mudança da percepção de seu próprio papel dentro da disputa política em seus respectivos países (Stepan, 1975).

A mudança na posição dos Estados Unidos representou a utilização de uma retórica na arena internacional de apoio aos regimes democráticos, o que resultou em mudanças nos regimes políticos na América Latina, que passaram a desenvolver instituições democráticas para aumentar sua credibilidade no sistema internacional.

No entanto, a utilização de variáveis referentes a fenômenos internacionais é dificultada pela existência de enormes diferenças entre as macrorregiões do globo. É importante salientar que o grau em que a política externa de determinado Estado pode influenciar outros é fortemente determinado pela proximidade geográfica e pela natureza das relações mantidas entre eles. Assim, baseando-se nos pressupostos apresentados, este artigo buscará explorar possíveis caminhos para explicar a influência de fatores internacionais em rupturas de regimes políticos na América Latina, enfatizando o possível papel que os Estados Unidos desempenharam, tanto na ascensão de regimes militares autocráticos durante o período da Guerra Fria quanto 
no processo de redemocratização durante o fim e o pós Guerra Fria; também são abordadas as análises sobre a difusão internacional da democracia.

A tendência que marcou esse período de redemocratização é mais bem percebida do que aquela de instalação de regimes autoritários, além de ser amplamente mais investigada pela academia que enfatiza os processos de difusão da democracia em escala mundial; porém, este artigo leva em consideração que as influências regionais e dos Estados Unidos foram, também, preponderantes na quebra dos regimes democráticos da América Latina durante a Guerra Fria, já que os processos de difusão de regimes políticos pelo globo podem induzir a transições de regime para outros tipos além do democrático (Gledistch, 1999).

Investigações anteriores que buscaram explicar os motivos da instabilidade política no subcontinente utilizaram fatores domésticos. Linz (1991), por exemplo, buscou explicar a fragilidade dos regimes democráticos da América Latina pela comparação das características estruturais e constitucionais dos regimes presidencialistas com os parlamentaristas. $\mathrm{O}$ autor considera os primeiros como menos estáveis devido a diversos fatores: existência de mandatos fixos dificulta a governabilidade em casos de crises políticas; maior rigidez no processo político, o que pode levar a que grande parte do eleitorado fique sem representatividade; cargo de presidente com dupla função - chefe de Estado e chefe de governo - ou seja, há concentração de poder nas mãos de apenas um líder, que não deve lealdade ao Congresso e poderá exercer o poder de forma majoritária; a polarização política no período pré-eleitoral. No entanto, a tese do autor só tem embasamento empírico pelo fato desse tipo de regime ser predominante na América Latina, ou seja, em países com baixos níveis de desenvolvimento enquanto os regimes parlamentaristas se concentram, por exemplo, na Europa Ocidental.

O fato de a América Latina ter presenciado diversos golpes de Estado durante o período da Guerra Fria dá o principal embasamento ao autor para afirmar que esse tipo de regime político é menos estável. Todavia, pode ser um indício da necessidade de se buscar outras explicações para a instabilidade dos regimes políticos da região.

De outra maneira, Cheibub (2007) busca variáveis diferentes para explicar o fato da expectativa de vida das democracias presidencialistas ser de 24 anos, contra 58 anos das parlamentaristas. Primeiramente, considera que a necessidade de se 
derrubar apenas uma figura, detentora de todo o poder no regime presidencialista, pode ser um fator que aumenta sua instabilidade.

O autor afirma que as democracias são consideravelmente mais instáveis na América Latina do que no resto do mundo, sendo a chance de ruptura de 1 em 19 na região, contra 1 em 70 no mundo. Entretanto, a explicação encontrada pelo autor não reside no fato de haver predomínio de regimes presidencialistas na América Latina, mas pela existência durante sua história de regimes autocráticos militares, um fator determinante para minar a estabilidade dos regimes políticos civis. Segundo os resultados de sua análise empírica, quando a variável referente ao legado do regime militar é inserida e a renda per capita controlada, o fato de o regime ser presidencialista não afeta sua durabilidade. Assim, se a democracia presidencialista instaurada for precedida por uma autocracia civil, tem a expectativa de durar 89 anos, contra 20 anos se precedida por uma ditadura militar, tendo uma expectativa parecida que um regime parlamentarista sob as mesmas condições. Portanto, a baixa durabilidade dos regimes presidencialistas se deve ao fato destes serem mais correntemente instaurados após autocracias de cunho militar, ou seja, pela conexão entre presidencialismo e militares, e não em falhas constitucionais. Sob outra perspectiva, Brinks e Coppedge (2006), ao considerarem variáveis referentes a fatores exógenos, não encontram correlações significativas entre durabilidade do regime democrático e sua natureza presidencialista.

Cheibub (2007) também afirma que a predominância de regimes presidencialistas na América Latina se deve a fatores históricos e não políticos. Por terem, os países, se tornado independentes durante um mesmo período (1804-1825), adotaram desenhos constitucionais parecidos, baseados na crença de que seria o mais adequado para garantir a "força" necessária para resolver problemas relacionados à instabilidade política e aos altos índices de desigualdades. Além disso, nesse momento, a escolha se limitava a duas possibilidades: república ou monarquia.

Apesar do autor não encontrar correlações significativas entre instabilidade dos regimes da América Latina e fatores exógenos, defende a tese de que a participação dos militares na política é um fator decisivo nas rupturas de regime. 
Sabendo das diversas possíveis explicações para a mudança de regimes na América Latina - predominantemente presidencialistas e palco de diversos golpes militares - a análise que segue buscará inserir uma nova variável que pode ser influente nos processos de ascensão de regimes autocráticos e democráticos, que remete à influência dos Estados Unidos em fortalecer o poder de determinado grupo organizado dentro dos cenários políticos nacionais. Assim, o artigo buscará encontrar embasamento na literatura disponível para explicar a importância que os Estados Unidos e o SI, fortemente ditado pelo mesmo no continente americano, tiveram nas mudanças de regimes políticos das Américas do Sul e Central.

O artigo é dividido em três partes, sendo que a primeira aborda a ascensão dos regimes autoritários no subcontinente durante a Guerra Fria; a segunda, seguindo a mesma linha, abarca o período de transição democrática contemporâneo a diversos países latino-americanos; na terceira são feitas as considerações finais.

\section{A ajuda militar norte-americana e os governos autocráticos na América Latina}

Visto que a América Latina é uma das regiões que passou por mudanças mais drásticas e concomitantes quanto aos regimes políticos desde o fim da Segunda Guerra Mundial, um estudo sobre a região é pertinente para entender como e quais fatores internacionais influenciaram nas mudanças de regimes políticos nacionais. A natureza dos regimes na América Latina passou por diversas transformações na segunda metade do século XX, sendo em parte democrática na década de 1950, majoritariamente autocrática a partir de 1972 e majoritariamente democrática a partir de 1994. Por isso, a região é considerada uma das mais homogêneas do mundo em relação aos níveis e tendências dos regimes democráticos (O'Loughlin et al., 1998). Por se tratar da área de mais forte influência dos Estados Unidos, país defensor da ideologia anticomunista durante a Guerra Fria e de valores democráticos a partir dos anos 1980 na fase final da Guerra Fria, a escolha desse período situado entre 1950 e 2000 parece ser adequada para investigar fatores relacionados ao sistema internacional e regional que influenciaram as mudanças de regimes nacionais. 
Assim, são procuradas relações de causalidade entre a influência do sistema internacional e de sua principal potência (em sua área de influência direta) e a estabilidade dos regimes políticos dessa região. Primeiramente, é investigado o papel da propagação da ideologia anticomunista e do apoio a regimes políticos autocráticos pelos EUA, e posteriormente, a defesa dos valores democráticos como condições a "inclusão/participação" no processo da globalização. O programa de assistência militar à América Latina da política externa norte-americana durante a Guerra Fria e as intervenções no Panamá em 1990 e no Haiti em 1994, no pós Guerra Fria, lideradas pelos EUA, seriam fatores que poderiam explicar os movimentos de ruptura de regimes democráticos e do posterior processo de redemocratização.

A consideração de fatores externos relacionados a um subcontinente a partir de questões referentes ao sistema internacional também podem resultar em explicações mais específicas do grau de estabilidade de um regime. O exemplo do golpe de 1973 na Argentina, que dentro da análise de Przeworski (2001) é o caso limite na definição da estabilidade a partir da renda per capita, mostra que tal golpe representou uma "anomalia" que poderia ser explicada por outras variáveis, tal como a proposta aqui, da influência das ideologias da Guerra Fria e o apoio dos EUA a governos de cunho anticomunista.

Visto que o papel dos militares na política é uma questão importante para explicar a fragilidade dos regimes democráticos na América Latina, o modo de interação desse segmento com os Estados Unidos e a mudança em sua autopercepção como ator na política doméstica, devem ser inseridos para se compreender de que modo o apoio externo concretizado pelos arranjos da Guerra Fria é preponderante para o ganho de poder pelas forças armadas.

Essa tese estaria em maior consonância com a análise do papel desempenhado pelos militares na política no Brasil, e de um modo geral na América Latina, realizada por Stepan (1975) em Os Militares na Política. O autor considera que uma mudança na percepção de seu papel na política, pelos militares - em grande parte influenciada pelo desenvolvimento de doutrinas de segurança nacional, homólogas àquelas oriundas das Escolas Superiores das Forças Armadas norte-americanas - foi uma pré-condição para os futuros golpes de Estado em países com Escolas de Guerra estruturas como aquelas 
existentes no Brasil, Peru e Argentina. A ascensão de regimes militares era considerada uma consequência aceitável para os Estados Unidos, desde que o novo regime garantisse a estabilidade política e manutenção do sistema capitalista. (Holden, 1993)

A mudança de autopercepção pelos militares se deve à diminuição da confiabilidade nos regimes democráticos em promover o desenvolvimento econômico. A ascensão de regimes militares está relacionada, no continente, com a persistência de altas taxas de desigualdade social, política e econômica após o processo de modernização, que resultaram em pressões populares para reformas destinadas a uma maior distribuição; assim, a intervenção militar apareceu como uma forma de reprimilas e garantir a continuidade do status quo (Stepan, 1975; O’Donnell, 1973).

A manutenção de privilégios pelas elites tradicionais está inserida dentro da própria lógica em que se formaram as instituições políticas no continente para organizar a produção colonial. A inserção dos militares na vida política explica as diversas rupturas de regime durante a segunda metade do século XX (Przeworski et al. 2000).

A mudança na tendência dos regimes na região pode, em parte, ser atribuída à mudança da ideologia política utilizada pelos Estados Unidos, assim como em um câmbio de percepção das elites sobre as instituições democráticas. Segundo Gleditsch e Ward (2006):

\footnotetext{
During the Cold War, ruling a country in an authoritarian fashion did not necessarily impose particular problems for a country's standing or a leader's ability to maintain ties with other states, as most countries were not democracies, especially the development world. Despite U.S rhetoric about protecting the free world, democracy was clearly not a requirement in the selection of allies and aid recipients (p. 921).
}

Durante a Guerra Fria, a política dos Estados Unidos para as Américas Central e do Sul tinha como objetivo específico garantir a manutenção das lideranças reformistas moderadas no poder, adversas a reformas de cunho popular consideradas como simpatizantes à ideologia comunista. O objetivo primordial era a manutenção da ordem interna, que era de vital interesse aos Estados Unidos por dois motivos: 1) garantia de sua própria segurança nacional para evitar possíveis influências da potência oposta (neste caso, a União Soviética) em uma área geograficamente 
próxima; 2) fornecimento de matéria-prima e de minerais estratégicos necessários para fomentar sua indústria armamentista.

A influência norte-americana na América Central foi e é tão forte que suas forças armadas e as elites agrárias locais foram as principais forças responsáveis pela formação dos Estados modernos na região, resultando em um modelo híbrido de Estado cliente composto por forças internas e externas que garantiram a manutenção da ideologia anticomunista e dos privilégios da classe política tradicional. Segundo Holden (1999), o objetivo dos Estados Unidos era modernizar esses Estados de modo a que se tornassem capazes de garantir a segurança interna e comandar um aparato de vigilância eficiente para controlar a ação de indivíduos.

Assim, os Estados Unidos agiam em três níveis sobre a região: 1) monitoramento unilateral de atividades de indivíduos suspeitos; 2) criação de redes e coletivização da vigilância na América Central; 3) relações bilaterais para a transferência de material e serviço.

O poder militar daquele país na América Central baseava-se em seis componentes: a) transferência de material e construção de bases militares; b) missões das Forças Armadas que administravam os programas de assistência militar; c) presença militar em bases e quartéis norte-americanos nos Estados vizinhos para treinamentos; d) programa de assistência policial para transferência de material e treinamento; e) relações próximas com Forças Armadas locais para incentivar a derrubada de governos hostis a Washington; f) manutenção de 2.000 a 5.000 soldados em Honduras para a utilização do país como sítio para treinamento. Por esses mecanismos, os Estados Unidos construíram relações estreitas com os militares locais, por meio de programas de ajuda militar que garantiram forte influência sobre importantes atores políticos locais que agiriam, caso fossem instaurados regimes de esquerda, ou permitiriam a manutenção de ditaduras militares aliadas. A falta de alternativa às elites locais levava-as a aceitar os programas de assistência: isso garantia a presença militar dos Estados Unidos na região através da justificativa de treinamento, o que permitia manter a hegemonia sobre a América Central e a ausência de insurgências populares (Holden, 1993). 
A institucionalização da ajuda militar como instrumento da política externa norte-americana para a região ocorreu durante a década de 1950. Já em 1955, todos os países da América Latina participavam do programa de assistência militar, com exceção de Argentina e México. Apesar dos estadunidenses não acreditarem na possibilidade de invasão soviética, principalmente antes da Revolução Cubana (em 1959), o plano inicial tinha como objetivo obter uma postura cooperativa dos Estados da região. No entanto, a ascensão de Fidel Castro intensificou a política de ajuda militar à região; assim, a estratégia de defesa hemisférica foi substituída por relações bilaterais que garantiam resultados mais rápidos e o melhor acesso a informações locais para monitorar possíveis insurgências populares.

O programa de assistência militar, no período inicial (1950-1961), que buscava garantir o acesso à região, passou a apoiar política de contra-insurgência (1962-1979) e teve sua estratégia redirecionada para conflitos de baixa densidade (1980-1990), sendo que o montante da ajuda militar cresceu vertiginosamente nesses períodos, passando de 74 milhões para 478 milhões de dólares no segundo período e 1,87 bilhões de dólares no terceiro (Holden, 1999).

A influência da superpotência na América do Sul não era tão forte como na América Central. Apesar de Stepan (1975) atribuir o golpe militar no Brasil à falta de habilidade política de João Goulart (1961-1964) e à crescente radicalização e bipolarização política interna, ele considera, também, que os Estados Unidos foram essenciais para enfraquecer o governo civil - que se aproximavam "perigosamente" da ideologia comunista - e para fortalecer o novo governo de Castelo Branco (19641967).

A preocupação com a contra-insurgência se iniciara na década de 1950 sob a liderança do principal teórico da Escola Superior de Guerra (ESG), Golbery de Couto e Silva, mesmo antes dos interesses dos norte-americanos no tema. No entanto, a própria criação da ESG está intimamente ligada às relações entre as Forças Armadas dos dois países iniciadas durante a Segunda Guerra Mundial. Argentina e Peru também formaram escolas de guerra semelhantes - respectivamente, Escuela Nacional de Guerra e Centro de Altos Estudos Militares. As duas tinham forte vinculação com a ideologia de segurança nacional norte-americana. Além disso, em 1963, já haviam se formado 16.343 oficiais latino-americanos na Escola de Guerra norte-americana 
localizada no Panamá, oficiais que posteriormente retornaram aos seus países ideologizados pela doutrina ianque (Stephan, 1975).

A emergência dos regimes militares esteve relacionada com mudanças na esfera internacional e doméstica entre as décadas de 1950 e 1960. A ascensão de Castro em Cuba e a expansão de doutrinas de guerra revolucionária resultaram em uma mudança da percepção dos militares sobre a leitura da conjuntura nacional e internacional, e sobre seu próprio papel na política doméstica. No Brasil, entre os anos de 1945 e 1964, desempenharam o papel de "padrão moderador" que se tratava da participação na política somente em casos de crise, pois após a restauração da ordem, devolviam o poder aos líderes civis. No início da década de 1960, com a descrença na competência do governo Goulart e do regime democrático em garantir o desenvolvimento, os militares passaram a acreditar em seu potencial para realizar tal tarefa, tão necessária à segurança nacional (Stephan, 1975).

O temor ao comunismo levou os militares a buscar medidas para evitar revoluções e a desenvolver doutrinas de contra-insurreição. Assim,

[...] percebendo que a estratégia da guerra revolucionária envolvia todos os níveis da sociedade, o conceito de segurança entre as Forças Armadas passou a abarcar todos os aspectos da vida social e política. Os militares começaram a preocupar-se com a ação cívica, com seu papel de "construtores da nação" e com planos globais de desenvolvimento. Estas respostas implicavam uma expansão considerável do papel dos militares e uma crença na legitimidade desses novos papéis. Todas essas ideias eram defendidas pelos Estados Unidos e ensinadas em suas escolas para militares latino-americanos (Stepan, 1975. p.128).

Apesar de demonstrar a forte influência da Guerra Fria e da Doutrina de Segurança Nacional norte-americana, o autor considera as mudanças na conjuntura doméstica como essenciais para a consolidação do golpe de 1964. A radicalização do Governo Goulart pela promessa de reformas de base e a possível mudança das regras do jogo através da realização de um plebiscito para mudar a constituição, diminuiu o apoio civil e a própria legitimidade do governo. Paralelamente, diminui, entre os militares, os defensores do constitucionalismo ou apolíticos, porque se basearam na percepção de que o próprio presidente estava quebrando os princípios constitucionais. 
Essa mudança nas relações de forças levou ao golpe de Estado em 1964 e, posteriormente, a instituição do regime militar no Brasil (Stephan, 1975).

$\mathrm{Na}$ visão de parte dos militares, a questão da segurança nacional estava intimamente relacionada com a necessidade de expansão econômica e esse seria o modo para se garantir contra possíveis insurgências. Esse padrão de transformação da percepção dos militares sobre a ameaça comunista, e seus estudos sobre desenvolvimento, teve características semelhantes em diversos países da América Latina. Além disso, a percepção do sucesso do modelo brasileiro em estabilizar a economia e barrar a quebra do status quo, incentivou os países vizinhos adotarem modelos semelhantes. Segundo O'Donnell (1973), o crescimento de poder dos tecnocratas, devido a sua especialização oriunda do desenvolvimento das escolas de guerra, gerou a crença de que eles seriam mais capazes de mudar o quadro de crise econômica e política dominante nos governos civis, o que resultou em um processo de instauração de burocracias-autocráticas na região.

A mudança dos rumos políticos na América Latina iniciou-se quando os governos militares passaram a enfrentar crises econômicas frente às mudanças na economia mundial, referentes à quebra do padrão dólar e dos choques do petróleo. Os países da Tríade (Estados Unidos, Europa Ocidental e Japão) como resposta às crises realizaram reformas em seus modelos macroeconômicos, o que marcou a ascensão do neoliberalismo. A doutrina neoliberal, conjuntamente com uma série de medidas de desregulamentação da economia, estava intimamente ligada a uma nova percepção do papel do Estado, que teria como uma das principais atribuições a garantia de direitos privados (Chesnais, 1996). A política neoliberal passou a ser condição essencial para a inserção dos países em desenvolvimento na economia internacional, o que levou à queda da legitimidade dos regimes militares na América Latina, constantemente identificados como protecionistas, nacionalistas e violadores de direitos de empresas multinacionais, com exceção de Chile e Argentina, que iniciaram o processo de liberalização sob o comando dos governos militares (respectivamente em 1976 e 1981).

Paralelamente, frente às pressões do Congresso norte-americano, a partir de 1976, ocorreu um aumento da preocupação em relação à violação dos direitos humanos durante o Governo Carter (1977-1981) e, posteriormente, uma mudança da 
agenda externa dos Estados Unidos durante o Governo Reagan (1981-1989) que passou a privilegiar parcerias com regimes democráticos e evitar ajuda externa a regimes autocráticos (Holden, 1993).

Essa mudança no quadro internacional foi determinante para diminuir a pequena legitimidade dos governos militares na América Latina e transformou a conjuntura que se demonstrara favorável durante a década de 1970, bem exemplificada pelo forte crescimento econômico da região no período (Bergesen, 1992). Dentro dessa nova conjuntura, foram criados incentivos para a redemocratização, o que ocorreu em diversos países da região: Peru (1980), Equador (1980), Argentina (1983), Brasil (1985), Uruguai (1985), Bolívia (1985), Paraguai (1989), Chile (1989), Honduras (1990), Panamá (1991), El Salvador (1991), Nicarágua (1996), Guatemala (1997) e República Dominicana (1997).

Para investigar esse fenômeno, os estudos de democratização sobre difusão são adequados. Mesmo que seja possível adaptar tais modelos para investigar também o modo como ocorreu a ascensão de regimes autocráticos durante as décadas de 1960 e 1970. Predominantemente, os estudos se concentram nos modos como a ideologia e a democracia são incentivadas a partir de diversos fatores exógenos, influenciando o nível de poliarquia existente nos diversos países do sistema internacional.

\section{A abordagem difusionista e a redemocratização da América Latina}

Outro caminho para buscar a explicação para a peculiaridade e contemporaneidade das mudanças de regimes na América do Sul e Central está nas abordagens emergidas após a terceira "onda" de democratização; aquelas que buscam em variáveis referentes a fatores exógenos explicações do por que a redemocratização ocorreu em um mesmo período de tempo em diversas partes do mundo (Huntington, 1991). Os principais indícios dessa percepção foram as segunda e terceira "ondas" de democratização após o fim da Segunda Guerra Mundial e da Guerra Fria, além da “onda" de autocratização na América Latina durante as décadas de 1960 e 1970, em 
que diversos regimes democráticos caíram devido a golpes de Estado (foram 97 golpes no total, entre os anos de 1945 e 2000, no subcontinente), baseados na mesma ideologia de segurança nacional (Brinks e Coppedge, 2006).

Foram, portanto, identificadas cinco "ondas" de mudança de regimes no século XX. O'Loughlin et al. (1998) alegam existirem dois fenômenos de difusão temporal de autocracias entre os anos de 1922 e 1942, e entre 1958 e 1975, e remete tais processos a dois movimentos: reversão em massa de regimes democráticos a autocráticos, como na década de 1960 e 1970 na África e na América Latina; e países independentes que ingressaram no sistema internacional sob governos autoritários. Por outro lado, Huntington (1991) encontrou três períodos na história de democratização, as "ondas" ocorreram entre os anos de 1826 e 1926, 1943 e 1962, e 1974 até hoje.

Apesar de essa literatura ter emergido no final do século $X X$ e se preocupar, primordialmente, em explicar o fenômeno da terceira "onda" de democratização, este tipo de modelo também pode ser adaptado para entender como a presença de regimes autocráticos em uma região e no mundo diminuem os custos de elites políticas locais em manter governos fechados. Assim, alguns trabalhos utilizam pontuações de regimes para entender os padrões de difusão ou apenas investigam a influência dos regimes vizinhos sobre determinado país, ou seja, servem também para descobrir se a difusão também existe em relação aos regimes autocráticos (Wejnert, 2005; O'Loughlin et al., 1998).

Para Whitehead (1996) a maioria dos países não gerou a democracia independentemente. Ele se baseou na percepção de que as correlações entre democracia e desenvolvimento explicam não mais que $70 \%$ da variância do nível da democracia e que processos de mudanças de regime já foram promovidos ou instituídos por forças externas através de incentivos, sanções ou uso da força. Essa recente corrente, que busca examinar o fenômeno de difusão dos regimes no mundo, utiliza diferentes abordagens para explicar as ditas "ondas".

Os trabalhos que utilizaram a abordagem difusionista, baseados em análises empíricas, geralmente têm como premissas comprovar a existência desse fenômeno e investigar como ele funciona. Para isso, utilizam as variáveis internas consideradas mais importantes como controle, para anular seus efeitos sobre a estabilidade do 
regime; ao isolar esses fatores encontram apenas a influência dos fatores externos. Os resultados encontrados demonstram que os fatores exógenos têm grande impacto sobre a natureza e a transição de regimes ao redor do mundo (Bollen, 1983; Gleditsch e Ward, 2006; O’Loughlin et al., 1998; Brinks e Coppedge, 2006; Wejnert, 2005).

O objetivo dessa revisão bibliográfica é embasar a ideia de que fatores internacionais foram influentes nos processos de autocratização e democratização da América Latina durante a segunda metade do século XX e enfatizar a necessidade de se analisar influências do sistema internacional sobre a região para entender porque esses processos de mudança de regime ocorreram conjuntamente e limitaram as perspectivas de atuação das elites políticas locais.

Os trabalhos sobre democratização baseiam-se em cinco protótipos de difusão: (1) inovação adaptativa, a partir do momento em que os países vêm os benefícios obtidos por aqueles que já adotaram tal tipo de regime; (2) imitação, quando as incertezas da eficiência dos regimes democráticos são diminuídas pelos exemplos de outros países; (3) promoção, coerção ou incentivo de outro país; (4) comunicação expansiva, resulta no conhecimento das normas democráticas por políticos em países autocráticos; e (5) contexto local, aceitação pela elite local de estímulos externos relacionado com as condições domésticas. (Huntington, 1991; STARR, 1991; O'Loughlin et al., 1998)

Para comprovar os fenômenos de difusão, os autores dessa corrente, geralmente, buscam coincidências espaciais e temporais nesses processos para investigar se quebras de regime em países vizinhos, ou em qualquer parte do globo, aumentam a probabilidade mesmo ocorrer em outros países. Brinks e Coppedge (2006) utilizam três variáveis para investigar os processos de difusão: “imitação ao vizinho", que considera o impacto do regime vizinho, é explicada como "a tendency for neighbouring conuntries to converge towards a shared level of democracy and nondemocracy" (p. 464); "influência de uma superpotência", impacto dos Estados Unidos e União Soviética sobre suas áreas de influência; e "tendências mundiais", que considera se há difusão relacionada ao número total de democracias ou autocracias no mundo. Dentro dessa linha, Przeworski et al. (2000) afirmam que as democracias se 
tornam mais estáveis na medida em que seu número cresce no mundo, mesmo controlando os mais importantes fatores domésticos.

A principal preocupação de Brinks e Coppedge (2006) para demonstrar que "a difusão não é ilusão" foi controlar as variáveis referentes a fatores domésticos e a atenção sobre a similaridade desses fatores em uma mesma região, o que distorceria os resultados em busca dos efeitos da difusão. Os autores encontraram significância estatística no efeito dos vizinhos, sendo que uma diferença média de 1 ponto nos mesmos resulta na expectativa de mudança de quase 0,25 pontos na escala da Freedom House sobre um país, tendo esse efeito diminuído constantemente quando os vizinhos se tornam mais próximos na escala da Freedom House. O efeito das tendências globais é ainda maior, pois a cada ponto aumentado na média global, é esperado um aumento de 0,5 pontos nos outros países. Além disso, foi encontrada significância no efeito dos Estados Unidos nos últimos 20 anos sobre sua esfera de influência, ou seja, em países que apresentaram melhores resultados em direção à democratização.

De modo semelhante, Gleditsch e Ward (2006), através de dados obtidos em modelos de regressão baseados em variáveis endógenas e exógenas, afirmam que a proporção de democracias vizinhas aumenta a probabilidade de uma autocracia cair e que a proporção de democracias em escala mundial aumenta as chances de transição democrática no mundo, apesar de não afetar a longevidade dos regimes livres. 0 âmbito regional é enfatizado quando eles afirmam que os regimes são geralmente similares em uma mesma região e há uma tendência de que as transições resultem em convergência de regimes nesta esfera.

Outra investigação sobre os processo de difusão foi realizada por O'Loughlin et al. (1998). Sua análise utilizou uma classificação baseada na escala geográfica para encontrar padrões de difusão espacial e temporal de regimes políticos; é baseada em três níveis: global ou macrolevel, regional ou mesolevel e estatal ou microlevel. A partir destes níveis, realizaram análises dos aspectos temporais e espaciais de forma separada e conjuntamente. Os autores encontraram regularidades geográficas e espaciais nas mudanças de regime político, tanto de autocracias para democracias como vice-versa, e consideraram como possíveis fatores influentes nesse processo, os contextos locais e regionais, pela similaridade entre características internas entre 
países vizinhos, crises enfrentadas por regiões do globo que levaram a novas dinâmicas políticas e cooperação dentro de grupos políticos e econômicos regionais que facilitariam a transmissão de modelos de instituições políticas.

O resultado mais importante para este artigo em relação à "onda de autocratização" no subcontinente, encontrado por O'Loughlin et al. (1998), é o forte e estatisticamente significante agrupamento espacial das mudanças de regime na América Latina. A proximidade geográfica foi central nesse processo por dois motivos: primeiro, os desafios econômicos e crises eram similares na região, sendo que o Brasil solucionou-os, a implantação do regime militar surgiu como um caminho a ser seguido; e segundo, os programas de ajuda militar dos Estados Unidos para a América Latina ajudaram os regimes recém-instaurados a suprimir movimentos de cunho popular e comunista a partir da ideologia de segurança nacional da superpotência, como já analisado anteriormente (Stepan, 1975); a ajuda econômica também teve papal importante na recuperação das economias nacionais.

De modo similar, o movimento de redemocratização na região, ocorrido nas décadas de 1980 e 1990, teve como ator preponderante o Estados Unidos. Durante a "segunda Guerra Fria", na presidência de Ronald Reagan (1981 - 1989), houve a substituição da antiga doutrina por uma agenda de incentivo à democracia através da ajuda externa direcionada ao desenvolvimento. Posteriormente, o fim da Guerra Fria e a ascensão de leituras do sistema internacional como unipolar resultaram no aumento de poder dos Estados Unidos e na consagração do modelo neoliberal como a solução para os países subdesenvolvidos se inserirem no mercado mundial. Esse fenômeno influenciou os países da América Latina a adotarem regimes políticos com maior transparência, modelos macroeconômicos incentivados pelo FMI e Banco Mundial, políticas de respeito aos direitos humanos. Este seria o caminho para melhorar sua imagem internacional do país e assim garantir maiores fluxos de investimento externo e conseguir crédito junto a bancos internacionais, medidas que poderiam retirar os países da crise econômica que datava da década de 1980 (Arbilla, 2000).

Uma inovação importante dentro da corrente difusionista, e pertinente para elencar mais um fator influente nas "ondas" ocorridas na América Latina, é introduzida por Wejnert (2005), a partir de uma análise de 187 países entre 1800 e 1990. A autora 
descobre que a significância dos indicadores de desenvolvimento sobre o nível do regime político perde força com a inclusão de variáveis de difusão. Ela utiliza 5 indicadores de desenvolvimento socioeconômico e 4 indicadores de difusão e introduz uma variável referente a eventos históricos, os quais seriam responsáveis por uma mudança massiva de regimes; paralelamente, também utiliza uma estrutura hierárquica de mudança anual dos níveis de regime dentro de cada país e de cada região.

Os momentos históricos influentes selecionados são: 1918-1922, fim da Primeira Guerra Mundial; 1933-1939, grande depressão; 1945-1959, pós-Segunda Guerra Mundial e redesenho do mapa mundial; 1955-1960, descolonização; 19621967, colapso de democracias frágeis nos novos Estados africanos; 1975-1985, efeitos da crise mundial do petróleo; 1989-1991, colapso do bloco socialista. Esses eventos tiveram efeitos sobre os tipos de regimes no mundo, sendo que os momentos após as duas Guerras Mundiais - pelas pressões dos Estados vencedores - e a crise do petróleo resultaram em aumento das democracias; e os momentos anteriores às guerras e dos colapsos dos regimes políticos na África representaram períodos de ascensão de regimes autocráticos.

A explicação para o aumento do número de democracias, vivenciado intensamente pela América Latina, a partir dos efeitos da crise do petróleo, pode ser também explicado por outra vertente que analisa as mudanças de regime a partir da teoria dos Sistemas-Mundo e das teorias de dependência, ao considerarem que a posição do país no sistema internacional (centro, periferia e semi-periferia) influencia nas mudanças de regimes políticos internas.

Nesta linha, Bergesen (1992) considera um fator influente na redemocratização da América Latina a crise econômica mundial do petróleo na década de 1970 . O autor faz uma análise dos ciclos da economia mundial, baseado nas idéias de Wallerstein (1991) e Arrighi (1994), dividindo-a em duas fases: A - momento de expansão puxado por uma economia nacional hegemônica; e B - economia mundial pluralista marcada por políticas protecionistas. Um período com características da fase B ocorreu entre 1975 e 2000 e levou o centro a buscar soluções conjuntas para controlar a economia mundial. Como reflexo, os países da semiperiferia, mais vulneráveis, sofreram com as flutuações dos preços dos produtos primários resultantes da política econômica do 
centro, e consequentemente, ocorreu a queda da legitimidade do Estado pelo descontamento social frente ao pequeno crescimento econômico e continuidade de altas taxas de desigualdade A resposta da semiperiferia, seria, segundo o autor, a reestruturação dos sistemas políticos domésticos.

Voltando à análise de Wejnert (2005), após considerar o efeito das 9 variáveis (endógenas e exógenas) e ter controlado a variável de eventos históricos, os resultados demonstram a necessidade em se considerar os efeitos da difusão de modo separado em cada região. A mídia, por sua vez, tem efeito positivo sobre o nível de democracia em todas as regiões com exceção do Oriente Médio em que o efeito é negativo. Por outro lado, na Europa Ocidental a educação não tem qualquer efeito enquanto a renda per capita domina como principal prognosticador. Esses resultados são importantes para defender a tese de que o fenômeno da mudança de regime é melhor explicado quando considerados conjuntamente os fatores exógenos e endógenos, além de analisar especificamente as condições históricas e a relação de uma região específica com o SI.

\section{Considerações finais}

Este trabalho buscou encontrar explicações para as "ondas" de "autocratização" (décadas de 1960 e 1970) e democratização (décadas de 1980 e 1990) na América Latina em duas frentes: através análise da influência dos Estados Unidos por meio de sua ajuda militar e da Doutrina de Segurança Nacional, assim como pelo incentivo aos regimes de direitos humanos e modelos macro-econômicos neoliberais; e por meio da discussão sobre pesquisas empíricas que analisam os processos de difusão que investigam os efeitos de fatores exógenos sobre o tipo de regime político nacional.

Apesar de não haver realizado nenhum estudo empírico, as informações reunidas são suficientes para confirmar o forte papel que variáveis exógenas exercem sobre mudanças de regimes políticos, principalmente na América Latina. A região, por ser uma área de influência muito forte dos Estados Unidos, foi muito influenciada pela 
ideologia propagada por essa potência durante a Guerra Fria e logo após seu final, por meio da tática de oferecer ajuda militar para ter influência sobre um importante ator político na região e pelas pressões a aceitação da nova agenda internacional dos anos 1990. No primeiro memento, o processo foi eficiente para garantir a não insurgência comunista na região, porém teve como resultado a propagação de regimes militares autocráticos na América Latina; no segundo, ajudou a aumentar a pressão sobre os regimes fechados em crise política e econômica.

Vale frisar o problema metodológico que aparece ao tentar isolar a influência do sistema internacional e dos EUA - principalmente porque sua política de ajuda financeira sempre esteve atrelada a exigência de adesão a certos padrões políticoeconômicos pelos latino-americanos - da influência do desenvolvimento econômico. Nos momentos de ruptura, os países passavam por crises econômicas, o que foi determinante para minar o regime. A influência do sistema internacional pode ser indireta, sendo assim, teria sido determinante para a formação do quadro de crise econômica na região, e este fator seria o responsável pelas mudanças de regime. No entanto, é importante lembrar a importância dos EUA e de seu domínio sobre a agenda internacional para os países da América Latina; a ajuda externa oferecida aos regimes aliados representava uma fonte importante para os Estados, principalmente na América Central.

Assim, as características da região como semiperiferia no mundo também foram influentes, já que os efeitos da crise mundial no final da década de 1970 foram "sentidos" fortemente na região, o que teria erodido a base de legitimidade dos governos autocráticos e resultado na busca de novos arranjos políticos para sanar os problemas econômicos e políticos existentes. Nessa perspectiva, a mudança da postura dos EUA também foi preponderante, já que o incentivo à adoção de medidas de desregulamentação na economia, a defesa de um novo modelo de Estado e dos valores democráticos e de direitos humanos, diminuíram as possibilidades de manutenção dos regimes autocráticos.

As análises difusionistas demonstram a necessidade em se considerar a influência de variáveis exógenas no comportamento dos regimes político nacionais. Além disso, também sublinharam a necessidade em se considerar de que modo essas variáveis determinam as conjunturas de modo diferente nas regiões do globo. 
A recente 'primavera árabe' é um acontecimento que representa a importância do contexto regional sobre os regimes políticos nacionais. Apesar dos analistas considerarem que as revoltas resultaram de uma conjunção de fatores sociais e políticos nacionais - tais como problemas econômicos, grande porcentagem de população jovem, longa vigência de regime político fechado, entre outros - a existência de influências externas e regionais na queda de regimes autocráticos é inegável. Além de ser possível identificar uma nova "onda" regional de democratização, o apoio às aspirações populares por parte da comunidade internacional (em alguns casos, os mesmos países que apoiavam o antigo regime autocrático) pressionou os ditadores através de sanções econômicas, apoio militar, ou meramente retórico, dependendo do caso específico.

No entanto, futuras investigações são necessárias para melhor entender os padrões de comportamento dos regimes políticos. Há necessidade de se realizar uma pesquisa empírica para investigar de modo mais concreto a influência do sistema internacional e de uma superpotência. Neste tipo de pesquisa, seria possível isolar os efeitos das principais variáveis explicativas sobre mudanças de regime e focar sobre fatores exógenos específicos influentes no caso latino-americano.

\section{Referências bibliográficas}

Almond, Gabriel. e Verba, Sidney. 1963. The Civic Culture: Political Attitudes and Democracy in Five Nations. Princeton, NJ: Princeton University Press.

Arbilla, José Maria. 2000. Arranjos Institucionais e Mudança Conceitual nas Políticas Externas Argentina e Brasileira. Contexto Internacional. Rio de Janeiro, vol. 22, no 2, julho/dezembro, p. 337-385.

Aron, Raymond. 2002. Paz e Guerra entre as Nações. Brasília: UNB.

Bergensen, Albert. 1992. Regime Change in the Semiperiphery: Democratization in Latin America and the Socialist Bloc. Sociological Perspectives, Vol. 35, No. 2, pp. 405-413

Bollen, Kenneth. 1983. World System Position, Dependency, and Democracy: The CrossNational Evidence. American Sociological Review, Vol. 48, No. 4, pp. 468-479. 
Brinks, David e Coppedge, Michael. 2006. Diffusion Is No Illusion: Neighbor Emulation in the Third Wave of Democracy. Comparative Political Studies, Vol. 39, No. 4. Austin: University of Texas, pp. 463-489.

Cheibub, José. Antônio. 2007. Presidentialism, Parliamentarism and Democracy. New York: Cambridge University Press.

Chesnais, François. 1996. A Mundialização do Capital. São Paulo: Xamã.

Gleditsch, Kristian. 1999. S. International Dimensions of Democratization. Glasgow: University of Glasgow.

Gleditsch, Kristian e Ward, Michael. 2006. Diffusion and the International Context of Democratization. International Organization, Vol. 60, No. 4. pp. 911-933.

Holden, Robert. 1993. The Real Diplomacy of Violence: United States Military Power in Central America, 1950-1990. The International History Review, Vol. 15, No. 2, pp. 283-322.

Holden, Robert. 1999. Securing Central America against Communism: The United States and the Modernization of Surveillance in the Cold War. Journal of Interamerican Studies and World Affairs, Vol. 41, No. 1, pp. v-30.

Huntington, Samuel. 1991. The Third Wave: democratization in the late twentieth century. Norman: Oklahoma University Press.

Huntington. Samuel. 1975. A ordem política nas sociedades em mudança. São Paulo: Edusp.

Keohane, Robert. 1984. After hegemony: Cooperation and discord in the world political economy. Princeton: Princeton University Press.

Leeson, Peter e Dean, Andrea. 2009. The Democratic Domino Theory. American Journal of Political Science 53, no. 3, pp. 533-551.

Linz, Juan. 1991. Presidencialismo ou parlamentarismo: faz alguma diferença?, IN: LAMOUNIER, Bolivar. (org.) A opção parlamentarista. São Paulo: Sumaré.

Lipset. Seymour Martin. 1967. O homem político. Rio de Janeiro: Zahar Ed.

Moore Jr., Barrington. 1975. Origens sociais da ditadura e da democracia. Lisboa: Ed. Cosmos.

Newton, Kenneth. e Norris, Pippa. 2000. Confidence in Public Institutions: faith, culture or performance? IN: PHARR, Susan. e PUTNAM, Robert. (eds.). Disaffected Democracies: What's Troubling the Trilateral Countries. Princeton: Princeton University.

O'Donnell, Guillermo. 1973. Modernization and Bureaucratic-Authoritarianism: studies in South American politics. Berkeley: University of California.

O'Loughlin, John et al. 1998. The Diffusion of Democracy, 1946-1994. Annals of the Association of American Geographers, Vol. 88, No. 4, pp. 545-574.

Przeworski, Adam et al. 2000. Democracy and Development: political institutions and wellbeing in the world, 1950-1990. Cambridge: Cambridge University Press.

Przeworski, Adam. 2001. Democracy as an Equilibrum. New York: New York University. 
Putnam, Robert, Leonardi Robert e Nanetti, Raffaella. 1993. Making Democracy Work: civic traditions in modern Italy. Princeton: Princeton University Press.

Remmer, Karen e Merkx, Gilbert. 1982. Bureaucratic-Authoritarianism Revisited. Latin American Research Review, Vol. 17, No. 2, pp. 3-40.

Starr, Harvey. 1991. Democratic Dominoes: Diffusion Approaches to the Spread of Democracy in the International System. The Journal of Conflict Resolution, Vol. 35, No. 2, pp. 356-381.

Stepan, Alfred. 1975. Os Militares na Política: as mudanças de padrões na vida brasileira. Rio de Janeiro: Artenova.

Waltz, Kenneth. 1979. Theory of international politics. 2 ed. New York: Mcgraw-Hill.

Wejnert, Barbara. 2005. Diffusion, Development, and Democracy, 1800-1999. American Sociological Review, Vol. 70, No. 1, pp. 53-81.

Whitaker, Arthur. 1960. Our Reaction to Communist Inflitration in Latin America. Annals of the American Academy of Political and Social Science. Vol. 330, pp. 103-115

Whitehead, Laurence. 1996. International Aspects of Democratization. Transitions to Democracy, vol. 3. Baltimore: Johns Hopkins University press, pp. 3-46. 